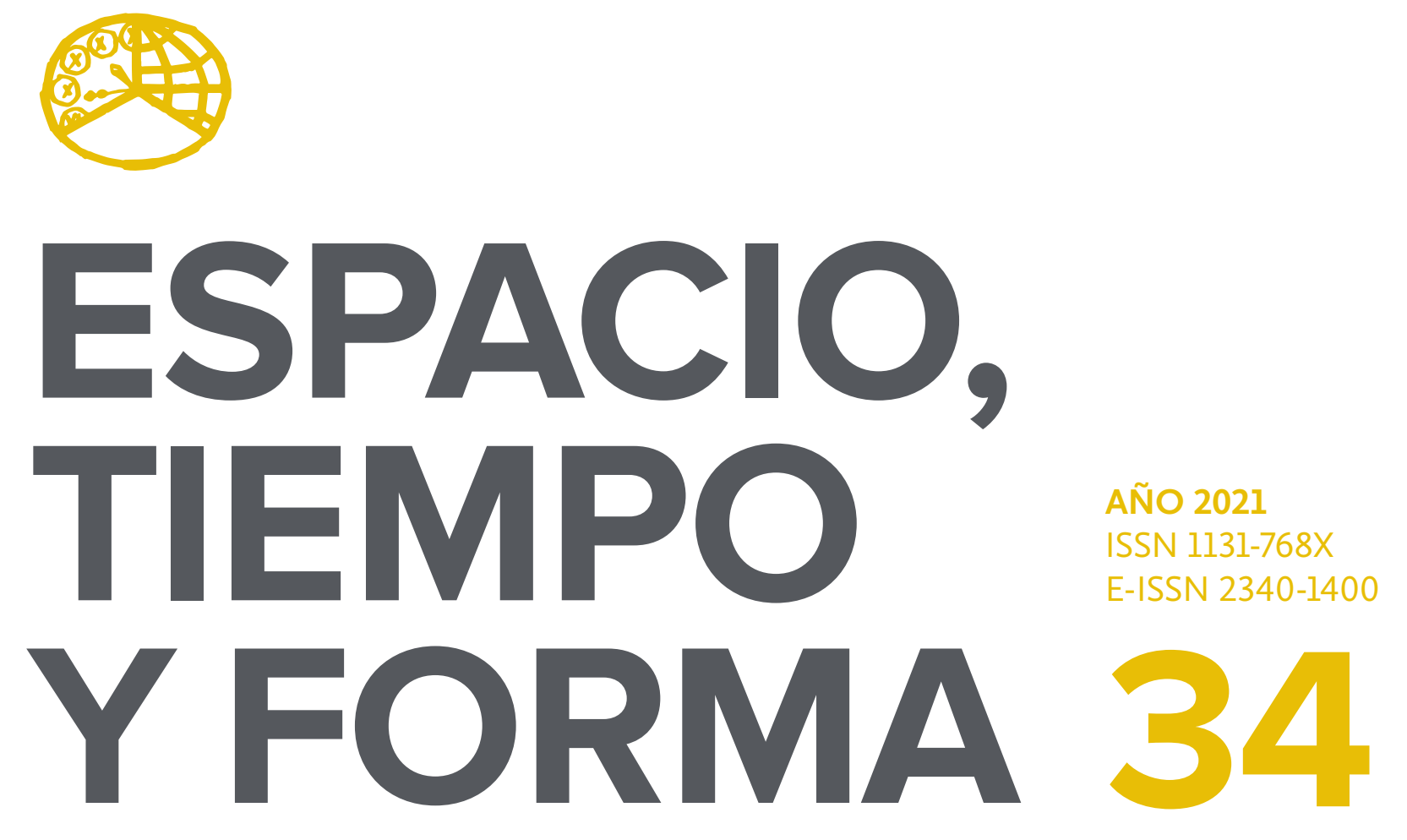

SERIE IV HISTORIA MODERNA

REVISTA DE LA FACULTAD DE GEOGRAFÍA E HISTORIA

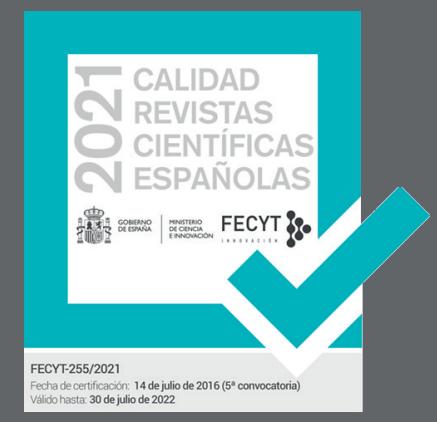




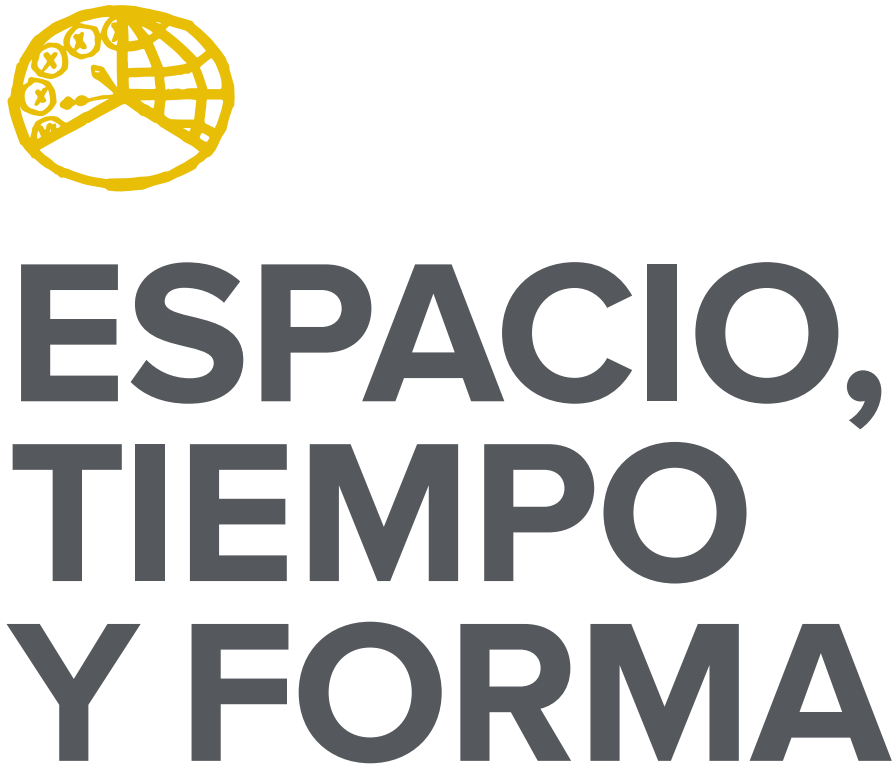

AÑO 2021

ISSN 1131-768X

E-ISSN 2340-1400

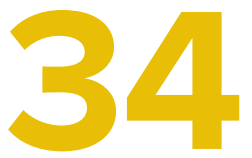

SERIE IV HISTORIA MODERNA

REVISTA DE LA FACULTAD DE GEOGRAFÍA E HISTORIA

DOI: https://doi.org/10.5944/etfiv.34.2021

\section{UกED}

UNIVERSIDAD NACIONAL DE EDUCACIÓN A DISTANCIA 
La revista Espacio, Tiempo y Forma (siglas recomendadas: ETF), de la Facultad de Geografía e Historia de la UNED, que inició su publicación el año 1988, está organizada de la siguiente forma:

$$
\begin{aligned}
& \text { SERIE I - Prehistoria y Arqueología } \\
& \text { SERIE II - Historia Antigua } \\
& \text { SERIE III - Historia Medieval } \\
& \text { SERIE IV - Historia Moderna } \\
& \text { SERIE V - Historia Contemporánea } \\
& \text { SERIE VI - Geografía } \\
& \text { SERIE VII - Historia del Arte }
\end{aligned}
$$

Excepcionalmente, algunos volúmenes del año 1988 atienden a la siguiente numeración:

$$
\begin{aligned}
& \mathrm{N} .^{\circ} 1 \text { - Historia Contemporánea } \\
& \mathrm{N}^{\circ} 2 \text { - Historia del Arte } \\
& \mathrm{N} .^{\circ} 3 \text { - Geografía } \\
& \mathrm{N} .^{\circ} 4 \text { - Historia Moderna }
\end{aligned}
$$

ETF no se solidariza necesariamente con las opiniones expresadas por los autores.

\author{
UNIVERSIDAD NACIONAL DE EDUCACIÓN A DISTANCIA \\ Madrid, 2021 \\ SERIE IV · HISTORIA MODERNA N. ${ }^{\circ} 34,2021$ \\ ISSN $1131-768 X \cdot$ E-ISSN 2340-1400 \\ DEPÓSITO LEGAL \\ M-21.037-1988 \\ URL \\ ETF IV · HISTORIA MODERNA · http://revistas.uned.es/index.php/ETFIV \\ DISEÑO Y COMPOSICIÓN \\ Carmen Chincoa Gallardo · http://www.laurisilva.net/cch \\ Impreso en España · Printed in Spain
}

(c) (7) (8) Esta obra está bajo una licencia Creative Commons Reconocimiento-NoComercial 4.0 Internacional. 


\section{MONOGRÁFICO · SPECIAL ISSUE}

LA POLÍTICA ULTRAMARINA DE LAS MONARQUÍAS

IBÉRICAS (CIRCA 1700-1750): UNA HISTORIA

DE FRACASOS Y ÉXITOS RELATIVOS

THE OVERSEAS POLICY OF THE IBERIAN MONARCHIES (CIRCA 1700-1750): A HISTORY OF FAILURES AND RELATIVE SUCCESSES 



\title{
DEFENDER NEGOCIOS EN TIEMPO \\ DE CONVULSIÓN POLÍTICA: \\ LAS ELITES MERCANTILES \\ FRANCESAS DURANTE LA GUERRA \\ DE SUCESIÓN ESPAÑOLA
}

\section{PROTECTING BUSINESS IN TIME OF \\ CRISIS: FRENCH TRADEMEN DURING THE WAR OF SPANISH SUCCESSION}

\author{
Guillaume Hanotin ${ }^{1}$ \\ Recibido: 15/12/2020 - Aceptado: 22/04/2021 \\ DOI: https://doi.org/10.5944/etfiv.34.2021.29360
}

\begin{abstract}
Resumen ${ }^{2}$
¿Cómo las elites mercantiles de las Dos Coronas borbónicas se adaptaron al fracaso de la guerra de Sucesión y a la reorganización de Europa después de Utrecht (I7I3)? Las relaciones entre mercaderes franceses y el comercio español son conocidas, sobre todo, desde la perspectiva de sus implicaciones en el emporio gaditano. El cambio dinástico, el enfrentamiento bélico, la construcción de la paz y la estabilización política del continente hasta los años veinte del siglo XVIII representaron evidentes desafíos. Los debates internos en el seno de los consulados y en las peticiones enviadas tanto al rey de Francia como al joven Felipe V, permiten de analizar las formas de adaptación a un contexto de fracaso político y, también, económico. En efecto, en los memoriales remitidos a la Junta de Comercio de Madrid o al Conseil de Commerce parisino, se encuentran discursos sobre la defensa del comercio y de sus efectos, teniéndose en cuenta el contexto militar. Si los negocios con América fue uno de los motivos de la guerra sucesoria, también sería un elemento clave en las reflexiones sobre las nuevas oportunidades económicas.
\end{abstract}

1. Université Bordeaux-Montaigne (CEMMC, EA 2958, F-33607 Pessac, France); guillaume.hanotin@u-bordeauxmontaigne.fr

2. Traducción realizada por Cristina Bravo Lozano (Madrid Institute for Advanced Study-Universidad Autónoma de Madrid). El presente artículo se inserta dentro del proyecto España y Francia: intereses dinásticos e intereses nacionales (1701-1733), concedido por el Ministerio de Ciencia, Innovación y Universidades (PGC2018-097737-B-100).

Abreviaturas utilizadas: Archivo General de Indias (AGI, Sevilla); Archivo General de Simancas (AGS, Simancas), Archivo Histórico Nacional (AHN, Madrid), Archives du Ministère des Affaires Étrangères (AMAE, París), Archives Nationales (AN, París), Archives Nationales de l'Outre-Mer (ANOM, Aix-en-Provence), Bibliothèque Nationale de France (BnF, París), Service Historique de la Défense (SHD, Vincennes). 
Palabras clave

Francia; España; comercio ultramarino; guerra de Sucesión española; siglo XVIII

\section{Abstract}

How did the mercantile elites of the Bourbon Two Crowns adapt to the failure of the War of Spanish Succession and the reorganization of Europe after the treaty of Utrecht (I713)? The relations between French merchants and Spanish trade are known above all from the perspective of their implications in the Cádiz. The dynastic change, the warlike confrontation, the construction of peace and the political stabilization of the continent until the I720's represented evident challenges. The internal debates at the consulates and in the petitions sent to the king of France as to the young Philip V, allowed to analyse the ways of adaptation to a context of political and also economic failure. Indeed, in the memorials sent to the Junta de Comercio of Madrid or in France to the Conseil de Commerce, it is possible to find speeches or rhetoric of the defence of trade, of its effects, taking into account the war context. If American trade was one of the reasons for the conflict, it was also an element in the reflections on the new economic opportunities.

\section{Keywords}

France; Spain; Ultramarine Trade; War of the Spanish Succession; $18^{\text {th }}$ Century 
El acercamiento político entre las cortes de Versalles y Madrid, causado por la muerte de Carlos Il y la ascensión al trono de Felipe V, nieto de Luis XIV, es bien conocido en sus dimensiones políticas, militares y diplomáticas, al igual que la guerra de la Sucesión española. El curso del conflicto fue una dura prueba para gran parte del continente europeo, movilizándose grandes ejércitos terrestres y escuadrones en el Mediterráneo y el Atlántico. Las motivaciones de este enfrentamiento son bien conocidas. Subyacían razones dinásticas ante la profunda rivalidad entre la Casa de Austria y la de Borbón, fundamentos políticos basados en la lucha contra la hegemonía de Luis XIV en Europa, y causas económicas ante la creciente competencia por el acceso al comercio americano. Para ingleses y neerlandeses, la participación en la guerra contra el Rey Sol era un medio de impedir que los franceses tuvieran vía libre para desarrollar acciones mercantiles. La firma del contrato de asiento de esclavos africanos a favor de la Real Compañía de Guinea el 2I de junio de I70I y, después, los diversos privilegios comerciales para la introducción de productos franceses en España alarmaron a las potencias europeas, contribuyendo en gran medida a la movilización contra las Dos Coronas borbónicas. El comercio fue, así, una cuestión esencial durante todo el conflicto e, incluso, un objeto de negociación en las conversaciones conducentes a la paz en I7I3 y I7I $4^{3}$. En ese sentido, es reseñable cómo la participación de Inglaterra -Gran Bretaña, desde I707- dependía estrechamente de la voluntad de los mercaderes de la ciudad de Londres, que estaban fuertemente representados y eran escuchados con atención en el Parlamento. De hecho, la victoria de los tories en I7II, más pacíficos que los whigs de la época, en parte se debería al importante papel desempeñado por los círculos mercantiles ${ }^{4}$.

La competencia por la defensa de los intereses comerciales y coloniales no se puede considerar como una cuestión específica de la conflagración europea derivada de la sucesión española, sino que adquirió una nueva dimensión en un conflicto cuyas repercusiones se extienden mucho más allá del continente. Para la monarquía de España, el cuestionamiento de su dimensión imperial emergió en un período tan temprano como el inicio del siglo XVI. Si tal rivalidad se expresó inicialmente entre castellanos y portugueses, poco después neerlandeses, ingleses y franceses también expresaron el mismo deseo de obtener territorios en el Nuevo Mundo. El surgimiento de diferentes imperios coloniales y la pugna por el control de las rutas marítimas y las tramas comerciales estructuraron la relación global de las soberanías europeas durante mucho tiempo. Las teorías mercantilistas se basaban en la aceptación de la emulación económica, a menudo resumida en la fórmula «la guerre d'argent» de Colbert, el emblemático ministro de Luis XIV. Conflictos, rencillas, anexiones y negociaciones propias del ámbito indiano marcaron las relaciones internacionales del continente europeo a lo largo del siglo XVII. Este influjo ultramarino condujo a la creciente integración de los intereses coloniales y comerciales en las negociaciones y tratados diplomáticos ${ }^{6}$.

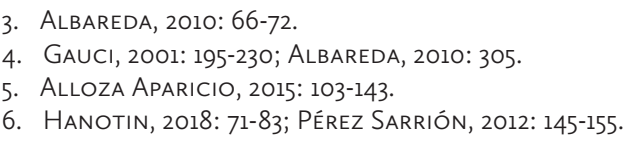


Los negociantes, comerciantes y mercaderes solían ser las primeras víctimas colaterales de los conflictos militares y los enfrentamientos marítimos. Se presentaba como una táctica legítima el ataque al tráfico mercantil y la incautación de los efectos de los vasallos del adversario. Las represalias eran tan comunes como la guerra misma y tales acciones están bien documentadas ya sea por la piratería, considerada como recurso habitual en un enfrentamiento regular entre dos príncipes, o, simplemente, por la confiscación de bienes salvaguardados en los almacenes de los principales comerciantes. La guerra mercantil se convirtió en una especialidad para ciertas ciudades como Dunkerque o Saint-Malo7. Las represalias contra las colonias de mercaderes extranjeros serían un arma que la monarquía de España, tanto como las demás, usó en determinadas ocasiones para defenderse de sus oponentes. Así, Felipe IV se sirvió de esta técnica contra los comerciantes ingleses en Portugal y Andalucía hasta que se restableció la paz en I630, y se retomó de nuevo a partir de $1652^{8}$. Por otro lado, en I635, cuando estalló el conflicto con Francia, el rey de España aplicó medidas similares a los súbditos de Luis XIII ${ }^{9}$. Durante el reinado de Carlos II, las represalias siguieron siendo numerosas, tanto que se multiplicaron por las múltiples guerras contra Luis $\mathrm{XIV}^{\mathrm{I}}$. Si el conflicto armado encuentra aquí una extensión en forma de la confiscación de bienes de los negociantes foráneos, esta práctica irrumpió a menudo como elemento común en las rutas a larga distancia y dificultó el tráfico regular. Las medidas eran, entonces, rápidamente relajadas o moderadas, máxime con la existencia de fronteras tan porosas que se asemejan más a espacios de intercambio que a límites definidos donde la soberanía pudiera imponer sus reglas, como demuestran los montes Pirineos a lo largo de los siglos modernos.

Las consecuencias políticas y económicas de las guerras son bien conocidas y están plenamente documentadas, ya que dieron lugar a constantes reclamaciones durante las negociaciones de paz. Las represalias se notificaban e imprimían, o se conocían a partir de los registros cuando se recaudaba un determinado impuesto ${ }^{\text {II }}$. Así pues, los efectos de la guerra son directamente apreciables y pueden ser objeto de un análisis detallado y objetivo. No ocurre lo mismo con la paz, dado que el restablecimiento de los vínculos comerciales y la reanudación del comercio podían llevar más tiempo y ser un proceso a largo plazo. A menudo, medido por el número de barcos que entraban en un puerto o simplemente por el número de mercancías contabilizadas en la aduana, el comercio reanudado en tiempos de paz es más difícil de detectar, aunque constituye una realidad ineludible para comerciantes y mercaderes. Durante mucho tiempo estos colectivos parecían preferir la paz a la guerra, pero esto obviaba los discursos belicistas y la adaptación de este gremio a los cambios en las relaciones militares y diplomáticas. Sus reacciones son menos conocidas que las represalias a las que podrían haber sido sometidos en el momento del conflicto. No obstante, su angustia y dificultades pueden detectarse gracias a las

7. Le MAO, 2015: 82-83; LeSPAGNOL, 1991.

8. Alloza Aparicio, 2015: 132; Alloza Aparicio, 2000.

9. Alloza Aparicio, 2005: 12-14; Hanotin, 2018: 34, 77-79.

10. LORENZO LOZANO, 2015, t. I: 201-266.

11. LORENZO LOZANO, 2015, t. II: 275, 307. 
quejas emitidas a sus respectivos soberanos, si bien se desconoce en gran medida cómo aprovecharon el retorno a la paz para sus propios asuntos e intereses.

Es inevitable considerar que los comerciantes se adaptaron a la conclusión de una vinculación o a las transformaciones introducidas en las relaciones entre dos potencias. Durante la guerra de Sucesión española, las cortes de Madrid y Versalles trataron de prolongar su nueva alianza, fundada por el acceso al trono hispano de Felipe $\mathrm{V}$ y con el establecimiento de una serie de acuerdos comerciales para promover los intercambios mercantiles a través de los Pirineos ${ }^{12}$. Esta política formaba parte de una estrategia más amplia conocida como de «unión de coronas», que correspondía al deseo de acercar ambas monarquías y, por extensión, a sus sociedades. El objetivo de este artículo no es volver a revisar esta cuestión, sino entender cómo las élites mercantiles trataron de apoderarse de esta idea y arrogársela pese a los límites y fracasos que se sucedieron en esta coyuntura.

\section{NEGOCIANTES E INSTITUCIONES COMERCIALES ANTE LA GUERRA DE SUCESIÓN ESPAÑOLA}

El conflicto sucesorio que comenzó en I7o r representó un doble desafío para las comunidades de comerciantes españoles y franceses. En primer lugar, tuvieron que adaptarse nuevamente a los trastornos inducidos por la guerra, a los que ya estaban acostumbrados. Si bien tuvieron que renunciar al comercio con Inglaterra, las Provincias Unidas y con todos los súbditos del emperador Leopoldo I, para algunos esta alianza hispanofrancesa fue sinónimo de oportunidades. Muestra de ello fueron los naturales de Saint-Malo, quienes enviarían numerosas embarcaciones al Mar del Sur -contraviniendo las leyes de la Carrera de Indias- debido a la dureza del conflicto y a la necesidad de encontrar recursos ${ }^{13}$.

La relación entre los círculos económicos o las sociedades mercantiles y los poderes fácticos está todavía por estudiar. Las instituciones que los reunían, como los consulados de mercaderes -no strictu sensu los de índole diplomática-, han sido estudiados en distintos trabajos historiográficos. Estas entidades, surgidas durante la Edad Media, conservaron un papel y un poder considerable durante la Modernidad ${ }^{14}$. En el caso de España, es bien sabido que el Consulado de Sevilla (o Consulado de cargadores de Indias), establecido en I553, se convirtió en un interlocutor esencial de la Corona y la Casa de Contratación para el comercio americano. Estos cuerpos gremiales se habían desarrollado primero en las ciudades mercantiles del Mediterráneo de los siglos XII y XIII, como Pisa, Génova o Venecia. En la península Ibérica, Valencia fue la primera urbe portuaria en tener una institución de este tipo, en I283, seguida de Mallorca en I343 y Barcelona en $1537^{15}$. Más tarde, aparecieron los consulados de Bilbao, Burgos, México (1592) y Lima (1593). Sus historiadores,

2. HANOTIN, 2018: 88-89.

13. DAHLGREN, 1909.

14. ULBERT, 2006.

15. VILA VILAR, 2016: 54 
caso de Enriqueta Vila Vilar y Guillermina del Valle Pavón, destacaron la necesidad de estudiar estas entidades con mayor profundidad, más allá de los aspectos institucionales, a fin de destacar mejor sus interacciones con la Monarquía ${ }^{16}$. A estas antiguas corporaciones hay que añadir la Junta de Restablecimiento del Comercio, creada durante el reinado de Carlos Il y remodelada en $1705^{17}$.

La situación es diversa en Francia, ya que las comunidades mercantiles estaban representadas por diputados en un Conseil de Commerce establecido por el contralor general de finanzas, Louis de Pontchartrain, después del Tratado de Ryswick (I697). También se crearon cámaras de comercio en Dunkerque (I700), Lyon (I702), Ruán (I703), Tolosa (I703), Montpellier (I704), Burdeos (I705), Lille (I7I4) y La Rochelle (I7I9) ${ }^{\text {I8 }}$. Otros tantos seguirían estableciéndose a lo largo del Setecientos. Su composición y funcionamiento fue bien estudiado en el siglo XIX, dejando su capacidad de acción en las sombras de la historiografía. Órgano consultivo el Conseil, como la Junta madrileña, es difícil medir el peso real de sus recomendaciones y proyectos.

Para comprender mejor las relaciones entre los círculos de poder y la comunidad económica es necesario analizar cómo estos grupos de comerciantes, dentro de los consulados, cámaras de comercio y corporaciones mercantiles, intervinieron con el gobierno para alcanzar sus intereses. Es la historia de una relación entre los súbditos y su príncipe y la imposición de una autoridad negociada. Los consulados de la monarquía de España no solo fueron tribunales para la resolución de disputas comerciales, sino que también actuaron como interlocutores con el rey. Por lo tanto, para comienzos del siglo XVIII, es menor el estudio de los flujos comerciales -ya ampliamente conocidos- que el de los intercambios y discusiones con la autoridad real que revelan cómo los mercaderes se adaptaron a la realidad de la guerra de Sucesión y la alianza entre Francia y España. El propósito de este artículo, por tanto, es destacar cómo los círculos comerciales se apropiaron de un acercamiento político y diplomático en su propio beneficio. Las memorias, las cartas dirigidas a los ministros del rey o la elaboración de material impreso en el contexto de un conflicto de calumnias entre los partidarios de Felipe V y los de Carlos III de Habsburgo, ofrecen un elenco documental de gran interés para comprender las relaciones entre los círculos comerciales y las autoridades.

\section{EL COMERCIO, UN DEBATE A DIFERENTES ESCALAS}

Más allá de las instituciones, los tribunales y los círculos cercanos al poder regio, los debates o las oposiciones relativas al comercio se convirtieron en temas controvertidos en los impresos que comenzaron a proliferar y a circular con mayor celeridad durante la transición entre los siglos XVII y XVIII. Acompañando a la creciente producción de las imprentas europeas, las polémicas de carácter comercial fueron

\footnotetext{
16. Vila Vilar, 2016: 19; VAlLe Pavón, 2016: 79.

17. Molas Ribalta, 1978.

18. FÉLIX, 1996: 414 .
} 
cada vez más numerosas en los folletos y demás formas de literatura ocasional. Antes del nacimiento de un «espacio público» (Habermas) en el Setecientos, las batallas de argumentos contrapuestos ya eran sumamente recurrentes ${ }^{19}$. Además de las disputas religiosas ligadas al surgimiento del protestantismo, las luchas políticas dieron lugar a lo largo del siglo XVII a la «guerras de plumas», según la fórmula de Heloise Hermant ${ }^{20}$. Las rivalidades mercantiles, marítimas y coloniales no quedaron fuera del alcance de esta práctica de confrontación retórica. Las instituciones republicanas de las Provincias Unidas ofrecieron una protección natural al florecimiento de los impresos que inundaron Europa. Entre I630 y i638, las reflexiones sobre el monopolio de la WIC (Compañía de las Indias Occidentales) sobre el comercio en Brasil descollaron con el horizonte del comercio del azúcar. Por ello, se imprimieron numerosos panfletos subrayando la existencia de una esfera transatlántica del discurso público neerlandés ${ }^{21}$. Es imposible saber con precisión cuáles fueron las consecuencias de este debate de opiniones enfrentadas. Cabe señalar, sin embargo, que la WIC cambió su posición al hacerse partidaria del libre comercio frente a otras fórmulas monopolísticas ${ }^{22}$. En I650, los mercaderes ingleses residentes en Bilbao disputaban en torno a la calidad de los textiles procedentes de su reino de origen. Se opusieron vivamente y escribieron memorandos impresos que luego fueron presentados a la institución encargada del comercio local. Unos primeros publicaron A Brief Narration of the present state of the Bilbao Trade [s. n., s. 1.] y sus detractores respondieron con An humble Answer to a Petition, desiring a regulation of the Biskey-trade by a consul and foure English factors [s. n., s. 1.] $]^{23}$. El idioma de la publicación, en este caso el inglés, plantea interrogantes sobre los objetivos de esta operación. ¿Se trató realmente de influir en las instituciones españolas o más bien en las autoridades inglesas a las que se apuntaba en el lance? Sea cual sea la respuesta, se plantea la inclusión de un debate comercial en una esfera pública que merece ser destacada.

El comercio, su libertad y su legitimidad estuvieron plenamente integrados en los instrumentos que contribuyeron a la politización de las sociedades, que era más avanzada en las soberanías que contaban un parlamento -como Inglaterra o las Provincias Unidas-, que en los que no lo tenían -caso de Francia-. Tan pronto como el duque de Anjou llegó al trono español, los libelistas y panfletistas ingleses tomaron partido para averiguar cuál sería la mejor posición que debía defenderse ante el conflicto que tendría lugar a continuación. De entre ellos, Daniel Defoe se involucraría notablemente en esta lucha. Ya en I700, publicó escritos en los que demostraba la necesidad de frustrar las ambiciones de Luis XIV. En The Two Great Questions Considered (I70I), denunció la amenaza que suponía la unión de Francia y España para el comercio inglés ${ }^{24}$. Además, este autor participó en la redacción de

\footnotetext{
19. HABERMAS, 1962.

20. HERMANT, 2012

21. VAN DEN TOL, 2017: 114.

22. VAN DEN TOL, 2017: 115 y 122

3. Alloza Aparicio, 2015: 139.

24. López CAMpillon, 2014: 36
} 
varias peticiones presentadas al Parlamento británico por las que se instaba a tomar partido en el conflicto sucesorio.

Las rivalidades económicas no solo se reflejaron en los impresos ingleses. También aparecen en la guerra de libelos y de propaganda librada entre todos los combatientes. David González Cruz, en su estudio de la guerra de palabras por la sucesión hispana, ha demostrado claramente cómo el comercio fue uno de los argumentos de los partidarios del archiduque Carlos de Austria -Carlos III- para denunciar los intereses de Luis XIV ${ }^{25}$. Además de convertirse en un nuevo «Atila», el Rey Sol fue acusado de querer hacerse con el control del comercio americano, lo que revelaría su voluntad hegemónica y aspiraciones universalistas.

En el plano interno de las diferentes potencias o soberanías, los círculos mercantiles fueron constantemente consultados por las autoridades regias durante la Edad Moderna. A día de hoy se sabe hasta qué punto se tuvieron en cuenta los intereses comerciales, marítimos y coloniales en las negociaciones diplomáticas europeas del periodo. La consulta era una práctica común durante el Antiguo Régimen, ya sea en Francia, España u otros territorios del Viejo Continente. En los estudios sobre el siglo XVI ha llegado a emerger, incluso, el concepto de "monarquía consultiva» ${ }^{26}$. La búsqueda de la opinión de un tercero, ya sea un príncipe, un ministro, un consejero o, incluso, los Estados Generales o los estados provinciales, parece que fue uno de los fundamentos del ejercicio del poder, incluso su esencia. En los siglos modernos, los sujetos consultaban por una amplia variedad de razones y, en particular, por los impuestos, los regalos gratuitos del clero y los privilegios y libertades celosamente guardados por sus poseedores. También se acudió a los comerciantes cuando se preparaba un reglamento o un edicto en materia mercantil. Esta tradición también parece marcar el tiempo en el Seiscientos, caracterizado tradicionalmente como un siglo de fortalecimiento de la autoridad real y el absolutismo. Sin embargo, oponerse a la monarquía del Quinientos, «consultiva», y a la monarquía seiscentista, «absoluta», resultó ser un enfoque cada vez más «falaz», en términos de Bernard Barbiche ${ }^{27}$. La organización política e institucional de la monarquía de España, como un agregado de reinos gobernados por consejos supremos, garantizaba la permanencia y continuidad del sistema consultivo ${ }^{28}$.

\section{PEDIR AL SOBERANO, UNA PRÁCTICA MERCANTILIZADA}

El contexto de exacerbación de las rivalidades coloniales, marítimas y comerciales favoreció el cuestionamiento de los soberanos por parte de unas comunidades mercantiles deseosas de proteger sus intereses y poner de relieve sus dificultades. Esta

25. Gónzález CRUZ, 2010:138.

26. ROBERTS, 2011: 89-108; CORNETTE, 2000: 34

27. «Au terme de cette analyse du régime politique de l'ancienne France, on retiendra qu'en définitive la monarchie n'a jamais cessé d'être un régime tempéré, et qu'il est peut-être fallacieux d'opposer monarchie consultative du $X V I^{e}$ siècle et monarchie absolue du temps de Louis XIV ». BARBICHE, 2001: 18.

28. Barrios, 1988; Cardim, Herzog y Ruiz IBÁÑEZ, 2012. 
no es una realidad nueva y una investigación a fondo permitiría descubrir muchos ejemplos en torno a ello. Las numerosas peticiones y demandas dirigidas al soberano o a sus ministros formaron parte de una costumbre y tradición propias de las relaciones entre un rey y sus reinos. El monarca consultaba a sus súbditos a través de las Cortes -en las coronas de Castilla (al igual que su reino agregado, Navarra), Aragón y Portugal- y los Estados Generales en Francia, aunque estos dejaron de convocarse tras I6I4, en un ejercicio que formaba parte del orden sociopolítico de ambas monarquías. Por lo tanto, era legítimo y común que los comerciantes se dirigieran a sus soberanos. Sus intervenciones aún son incógnitas, al no conservarse o estar dispersas. Además, en el mundo de la corte, resulta imposible seguir los intercambios orales que eran comunes a tales procesos de negociación. Sin embargo, es necesario analizar mejor la interacción entre el mundo mercantil y los círculos de poder sobre la base del discurso producido por el primero para defender sus intereses.

Si bien la historiografía ha puesto de relieve los intereses comerciales de la guerra de Sucesión española, aún no se han aclarado las preocupaciones de las élites mercantiles y su adaptación al nuevo contexto político y a la realidad de una alianza franco-española. La correspondencia dirigida a los secretarios de Estado y distintos embajadores, así como las quejas de los consulados y las memorias conservadas por la Junta de Comercio madrileña y el Conseil de Commerce francés, proporcionan algunos elementos iniciales de respuesta, aunque todavía son provisionales.

En una economía con medios limitados, la relación entre los comerciantes y el poder se inscribió en un sistema de interdependencia mutua. El príncipe necesitaba recursos fiscales para financiar su política y, por lo tanto, sus ministros trataron constantemente de aumentar sus recursos. Para ello, crearon y multiplicaron los impuestos, haciéndolos situar lo más posible en el comercio. Por consiguiente, toda la actividad mercantil estuvo cargada de impuestos, dando lugar, a menudo, a fraudes ${ }^{29}$. Los vínculos entre la presión fiscal de la Corona y las dificultades económicas de Castilla en el siglo XVII han sido reconsiderados por José Manuel Díaz Blanco en su ensayo Así trocaste tu gloria (20I2). Comparando las políticas impositivas llevadas a cabo durante los reinados de Felipe IV y Carlos II, este autor muestra que, aunque los excesos tributarios precipitaron la crisis de los años I620I660, la reforma fiscal de los años I660-I66i no tuvo un efecto acelerador en la recuperación de los años I660-I700 ${ }^{30}$. Así, los vínculos entre la presión fiscal y la actividad comercial son obvios, pero no inequívocos ${ }^{31}$.

Con la imposición de una nueva tasa, las élites mercantiles podían presionar a su príncipe, alertándole del riesgo de rarefacción de especies metálicas y de una forma de anemia comercial. A continuación, solicitaban exenciones y un mayor alivio fiscal para dedicarse a sus negocios y mantener la regularidad en los intercambios, lo que a su vez aceleraba la circulación del dinero. La saca de moneda al extranjero se consideraba indicativa de un déficit en la balanza comercial que los

29. JAMBU, 2007.

30. DíAz BLANCO, 2012: 237-239.

31. Díaz BLANCO, 2012: 282. 
mercantilistas aborrecían. Los contemporáneos fueron muy conscientes de ello, como lo demuestran las preocupaciones de las autoridades aragonesas -caso de la Junta Grande o de Comercio fundada en I674 por su virrey, Juan José de Austriaante la creciente salida de capitales con destino a Francia durante la segunda mitad del siglo $\mathrm{XVII}^{32}$. En este escenario económico, la riqueza de un príncipe se medía, primero, por la cantidad de metales preciosos que poseía. El oro y la plata disponibles se utilizaron como estándar en todos las monarquías, repúblicas y principados europeos, ya que la característica física de estos metales era que podían ser transformados muchas veces. Los mercantilistas vincularon estrechamente los recursos financieros del soberano a las condiciones del comercio. Así, los ministros de un príncipe y los comerciantes dependían de forma permanente unos de otros y no podían estar separados. Todas las intervenciones de las élites mercantilistas deben ser analizadas a la luz de esas relaciones que permitieron comprender cómo se adaptaron a las realidades políticas y a los trastornos de las relaciones internacionales. De este modo, la presión fiscal ejercida sobre el comercio, la fuerza del mercado y la circulación de las especies metálicas fueron indisociables.

\section{NEGOCIAR LA PRESIÓN FISCAL O FINANCIAR LA GUERRA}

Desde el comienzo de un conflicto, se incrementaba la búsqueda de recursos financieros. Entre los medios extraordinarios movilizados, los soberanos también exigieron «donaciones gratuitas» o donaciones forzadas. Era una especie de impuesto adicional que se imponía a las provincias y a las distintas órdenes. Estas concesiones gratuitas -donativos- se multiplicaron durante el reinado de Felipe IV. Hubo algunos en I629, I63I y I635. Tales aportaciones pecuniarias se situaban no solo sobre un orden privilegiado, sino que eran extensibles a todas las comunidades que conformaban la sociedad. Durante la guerra de Sucesión española, fueron muy numerosas. Los diferentes reinos de la Corona castellana proporcionaron una ayuda sustancial a Felipe V en I705: el donativo de Andalucía reportó 4.906.556 reales, mientras que el de Castilla ascendió a 4.I64.702 reales ${ }^{33}$. La provincia de Guatemala también proporcionó I7.0oo pesos para ayudar con los gastos militares ${ }^{34}$. La audiencia de Santo Domingo hizo lo mismo y Santa Marta financió la restauración de su fuerte ${ }^{35}$. El I8 de octubre de 1707, un decreto real impuso uno a los miembros del clero secular, que fueron invitados a participar en el esfuerzo de la guerra para «proteger la fe, mantener la monarquía, el honor de la

32. Mateos Royo, 2004: 171-174, 180.

33. AHN, Estado, legajo 772. Copia de real decreto de Felipe $V$ relativo al donativo general, Madrid, 3 de enero de 1705 .

34. AGI, Audiencia de Panamá, legajo 219. Carta de Toribio de Cossío al marqués de Mejorada, Panamá, 8 de febrero de 1708 .

35. AGI, Audiencia de Santo Domingo, legajo 251. Carta de la audiencia de Santo Domingo a Felipe V, Santo Domingo, 28 de septiembre de 1705; AGl, Audiencia de Santa Fe, legajo 504. Carta de Alonso Varela a Felipe V, Cartagena de Indias, 30 de enero de 1708. 
nación ${ }^{3^{6}}$. Estos donativos también se instrumentalizaron como forma de castigo, como acaeció en I707 en Aragón, cuando se impuso su pago a los partidarios del archiduque $\mathrm{Carlos}^{37}$.

En este marco impositivo, las comunidades mercantiles también mostraron su preocupación. En I715, la Junta de Dependencias de Extranjeros insistió en que los franceses establecidos en Valencia debían involucrarse en el donativo que se impuso a la ciudad ${ }^{3}$. El consulado de Sevilla, como el de Ciudad de México, participaron en términos de igualdad. No se trataba de cónsules foráneos a la cabeza de una diáspora de mercaderes, sino de cómo este tipo de corporaciones agrupaban en torno a sí a los comerciantes y súbditos del rey de España. Durante la guerra de Sucesión se renovó esta antigua práctica de acudir a las comunidades mercantiles. Comparando Francia y España, se observa exactamente el mismo proceso y tales donaciones gratuitas, forzadas o indultadas, se obtuvieron a cambio de una compensación para los mercaderes. Así pues, las negociaciones a las que dieron lugar esos pagos revelan preocupaciones similares y a veces contrapartidas indirectas.

Durante el reinado de Carlos II, el Consulado de Sevilla, por ejemplo, pagó caro su apoyo financiero a la Monarquía para financiar las guerras contra Luis XIV. La ciudad hispalense, amenazada por el auge de Cádiz, usó el pago de los consiguientes fondos a la corona para obtener ventajas políticas. José Manuel Díaz Blanco analizó pormenorizadamente el triunfo político de Sevilla, que logró hacer retroceder cualquier idea de liberalización comercial que beneficiara a la urbe gaditana como señal de una negociación exitosa ${ }^{39}$. En I666, el Consulado de Sevilla llamó la atención de la reina gobernadora Mariana de Austria sobre la manipulación fraudulenta que hizo Francisco Báez Eminente, el arrendador de los almojarifazgos, un impuesto aduanero sobre los productos procedentes de América. Al aplicar una fuerte tasa a los comerciantes hispalenses, desvió el tráfico de mercancías a Cádiz y, por extensión, los mercaderes locales se enfrentaron a la ruina total. Por consejo de una junta formada para estudiar el asunto, la regente decidió eliminar los usos y costumbres que habían estado vigentes en Cádiz desde i66I para concentrar toda, de nuevo, toda la actividad en Sevilla ${ }^{40}$. Esta decisión puede entenderse como una disposición antifraude tradicional. También puede analizarse como un compromiso entre la Corona y el Consulado, institución que aceptó proporcionar asistencia financiera a la soberana. A este respecto, el castigo infligido a Cádiz recuerda al impuesto cargado por Felipe Il y Felipe III a los comerciantes extranjeros, de nuevo, a cambio de ayuda económica. Por el contrario, la negativa del Consulado a contribuir a la financiación de la guerra de Holanda contra Luis XIV, en I676, tuvo como consecuencia el correspondiente castigo a Sevilla: Cádiz recuperó el Juzgado y Tabla de Indias, una

36. AHN, Consejos suprimidos, libro 1475. Real decreto de Felipe V sobre el donativo forzoso, Madrid, 18 de octubre de 1707.

37. AHN, Estado, legajo 312. Carta del obispo de Zaragoza a Joseph de Grimaldo, Madrid, 13 de septiembre de 1707.

38. AHN, Consejos, libro 683/4, expediente 232. Consulta de la Junta de Dependencias de Extranjeros, Madrid, 20 de enero de 1715

39. Diaz Blanco, 2012: 243.

40. DIAZ BLANCO, 2012: 240-242. 
especie de anexo aduanero de la Casa de Contratación ${ }^{41}$. Se puede afirmar, por tanto, que los privilegios comerciales se pagaron muy caros a la Corona.

Al igual que el Consulado de Sevilla, el de México participó en la financiación durante la guerra de Sucesión española. Esta institución negoció el alivio económico para Felipe $V$ a cambio de una relajación de la política de la restricción del comercio entre Nueva España y Asia a través del océano Pacífico. La corte de Madrid deseaba prohibir la importación de seda y varios textiles chinos ${ }^{42}$. El comercio con el Lejano Oriente fue un tema recurrente en los debates sobre el comercio, en particular, en su junta privativa ${ }^{43}$. En I706, el monarca Borbón emitió un decreto para restringir la introducción de productos asiáticos en Perú, renovando una disposición aprobada cuatro años antes ${ }^{44}$. Esta política se dirigió a limitar la fuga de dinero hacia la China manchú. De hecho, los priores del consulado de la ciudad de México, Luis Sánchez de Tagle y su sobrino Pedro Sánchez de Tagle estaban particularmente interesados en este negocio ${ }^{45}$. Tras un conflicto entre el virrey duque de Albuquerque y el Consulado, Felipe $\mathrm{V}$ recibió 39.500 pesos en I704. Dos años después, la difícil situación empujó al monarca a pedir un nuevo esfuerzo económico. La mencionada corporación novohispana se negó, a lo que el virrey negociaría un préstamo de 700.000 pesos al que los miembros consulares accederían a aprobar sin intereses. También aportaron 96.500 pesos, que se sumarían a una cantidad recaudada por el pro rex. Albuquerque podría, entonces, enviar un millón de pesos a finales de I706, importante ayuda económica que llegó a Brest en marzo de $1707^{46}$. A cambio de todas estas sumas, el virrey de Nueva España aplazó la aplicación de las restricciones comerciales decididas en I702 supervisó el galeón de Manila, llegado el mismo mes de diciembre de $1706^{47}$. El duque diferiría, por tanto, la adopción de la política madrileña para obtener, en cambio, ayuda financiera. Según Guillermina del Valle Pavón, el préstamo concedido por el consulado sería también la contrapartida de la renovación de la alcabala para el período I709-I723. Las autoridades reales temían que se concediera a un comerciante, Joseph de Zozaya, para obtener más ayuda financiera. En I707, Albuquerque consiguió, además de las sumas ya proporcionadas, 50.000 pesos adicionales bajo préstamo. Tanto el Consulado de México como el de Sevilla fueron exigentes en sus negociaciones con la Corona, tanto que esta última vendería su protección o la renovación de privilegios o ventajas a un alto precio.

Esta práctica también fue muy común en Francia. Los ministros de Luis XIV lograron el apoyo de los círculos comerciales a cambio de compromisos para favorecer sus negocios. Durante la guerra de Sucesión, las soluciones encontradas

41. DiAZ BLANCO, 2012: 254 .

42. AMAE, Correspondance Politique, Espagne, tome 185, f. 97. Traducción de la tarifa adjunta al proyecto formado en Madrid para la nueva normativa comercial en las Indias, junio de 1708.

43. AMAE, Correspondance Politique, Espagne, tome 157, ff. 180v-181. Memoria de lo que se hizo con motivo de la salida de los galeones y de la flota y de lo que se estableció en la junta formada para el restablecimiento del comercio en las Indias, Madrid, 3 de febrero de 1706.

44. AMAE, Correspondance Politique, Espagne, tome 163, ff. 291-292. Carta de Chamillart a Mesnager, París, 28 de marzo de 1706. VALLE PAVón, 2016: 82.

45. Valle Pavón, 2016: 81.

46. SHD, $\mathrm{A}^{1} 2048$, 177. Carta de Amelot à Chamillart, Madrid, 14 de marzo de 1707

47. Valle Pavón, 2016: 84. 
permitieron llenar el tesoro real y pagar los gastos militares con la contraprestación de acceder a las demandas de los mercaderes. Así, en I709, una resolución del Conseil d'État ordenó que se impusiera un indulto del $6 \%$ a todos los retornos de la Mar del Sur, debiéndose entregar los beneficios a Felipe V. Inmediatamente, los hombres de negocios se quejaron al contralor general de Finanzas, Nicolas Desmaretz. En su instancia señalaban cómo ya habían pagado los derechos debidos al rey Felipe conforme a las órdenes de cada oficial local español. También afirmaban que el escuadrón naval proporcionado por el monarca francés y que se había encargado de escoltarlos hasta Perú no había cumplido con presteza su misión, sino retrasar el convoy mercantil. El diputado de comercio de Nantes, Des Casaux du Hallay, elevó entonces el asunto a Desmaretz ${ }^{48}$. El indulto no fue levantado, pero se hizo una importante concesión a favor de los mercantes: sería retirado a cambio de la importación de granos. En medio de la crisis vinculada al Grand Hiver (enero de I709), el contralor general tuvo que abastecer al reino con trigo para paliar su escasez crítica. Esta urgencia era en I709 tan fehaciente y necesaria como la provisión de fondos a los ejércitos reales. Los mercaderes encontraron por esta vía la solución a sus problemas, la cual sería confirmada por una sentencia del Conseil d'État del 9 de julio de ese mismo año ${ }^{49}$. Luis XIV renunció a la retirada del indulto a favor de Felipe $\mathrm{V}$ a cambio de la importación del grano a razón de un barril por cada mil piastras. Así pues, la compra de cereales fue la contrapartida de una exención. Además, Desmaretz encontró un comerciante capaz de traer trigo de España, donde la cosecha sí había sido abundante ${ }^{50}$. Pierre Fontaine, un mercader francés asentado en Cádiz, solicitó los permisos necesarios para la exportación al reino galo ${ }^{51}$. Esta provisión cerealística permitió, como contrapartida, cierta recuperación de la economía española a través del flujo monetario. Como en los ejemplos anteriores, los círculos comerciales se adaptaron a las circunstancias políticas y contaron con un compromiso con la Corona entre sus privilegios y un precio a pagar.

La intensa mediación llevada a cabo por Des Casaux du Hallay no fue neutral. Era uno de los principales comerciantes del reino. Afincado en Nantes, era el diputado de la ciudad en el Conseil de Commerce. Sus posiciones son bien conocidas, ya que escribió una memoria sobre el comercio en I70I muy alabada por sus contemporáneos ${ }^{52}$. Además, está probado que este sujeto traficó directamente con la América española. En febrero de 1707 se comprometió con otros comerciantes a entregar a la Casa de la Moneda francesa la plata traída de las Indias de Castilla ${ }^{53}$. De hecho, era

48. Carta de Des Casaux du Hallay a Nicolas Desmaretz, París, 20 de abril de 1709, cfr. DE BOISLISLE ET DE BROTONNE, 1897: 128.

49. Sentencia impresa del Conseil d'État, París, 9 de julio de 1709, París: F. Léonard, 1709.

50. AN, G7 15. Carta de Desmaretz a Amelot, Versalles, 4 de agosto de 1709.

51. AN, G715. Carta de Desmaretz a Amelot, Versalles, 16 de julio de 1709. Es un comerciante que se estableció en el siglo XVII y cuya casa comercial continuó funcionando en el siglo XVIII. MÉZIN, 2016: 39; Relation de ce qui s'est passé dans les trois voyages que les religieux de l'ordre de Nostre-Dame de la Mercy ont faits dans les États du roy de Maroc pour la rédemption des captifs en 1704, 1708 \& 1712, París: Chez Antoine-Urbain Coustelier, 1724: 147.

52. QUÉNET, 1978: 453.

53. AN, G7 1421. Diversas cartas de comerciantes entregando sus remesas de plata a la casa de la moneda, febrero de 1707. Estos fueron La Lande Magon, Blampignon Baillon, Grandville Loquet, Danycan, Des Casaux, Chipaudière Magon y L'Evesque. 
transportada en el mismo convoy que el enviado por el virrey novohispano duque de Albuquerque tras su compleja negociación financiera en Ciudad de México. El millón de pesos enviado por el pro rex y que llegó a Brest en febrero de I707, escoltado por un escuadrón militar a cargo del marino Chabert, involucró a muchos actores secundarios. Parte de este dinero pertenecía a comerciantes franceses que luego negociaron con el contralor general de Finanzas la exención de la confiscación con la que fueron amenazados. Posteriormente, acordaron pagar un bajo precio por él, ayudando así a aliviar el debilitamiento del comercio debido a la falta de liquidez ${ }^{54}$.

Finalmente, el diputado por Nantes fue apoyado por Nicolas Desmaretz. Este último intervino en I709 a su favor, en particular, para recordar al embajador de Luis XIV en Madrid, Michel Amelot de Gournay, que debía ser tratado como los comerciantes españoles exentos de indultos por parte del rey de España ${ }^{55}$. Llevar el dinero a la ceca para ser acuñado fue la contraprestación negociada, ya sea en beneficio de Felipe V o de Luis XIV. Al igual que en el caso del Consulado de México o, previamente, el de Sevilla, las negociaciones entre los comerciantes y la corona dieron lugar a un compromiso en el que se equilibraron las necesidades fiscales de la Monarquía y el mantenimiento del comercio. Los flujos de oro y plata de América durante la guerra de Sucesión española están bien documentados y analizados. Muchos historiadores, como E. Dahlgren, E. Pérez-Mallaina, H. Kamen y P. Hrodej, han destacado la ambigüedad o la duplicidad de los ministros del Rey Sol, que condenaron oficialmente las salidas francesas a la Mar del Sur mientras concedían discretamente pasaportes para viajar a dicho ámbito ${ }^{56}$.

Sin embargo, lo que puede parecer una renuncia de la Corona a preservar sus intereses fiscales debe analizarse, de hecho, en el marco de una negociación destinada a obtener apoyo financiero de los círculos mercantiles. En otras palabras, el fraude al que daría lugar este impuesto se considera menos importante que la compensación obtenida. Los indultos fueron utilizados por Luis XIV como un medio de presión sobre los comerciantes para hacer que el dinero dinamizase el comercio regnícola. Se concedieron exenciones a cambio de una compensación: en I705, como en I707, fue el compromiso de abastecer a las casas de moneda y, en I709, sería el suministro de grano al reino ${ }^{57}$. Por lo tanto, las discusiones entre los comerciantes y la Corona formaron parte de un esquema más complejo que la mera realidad de los impuestos situados sobre una actividad económica. Se tuvieron en cuenta otros intereses: los del rey frente a los de los comerciantes que se adaptaron a un contexto político inestable. Estas conversaciones y acuerdos revelan fuertes similitudes entre las prácticas mercantiles y políticas y, sobre todo, una semejanza entre las realidades de la monarquía de España y las características del reino de Francia. En otras palabras, los comerciantes y consejeros de los príncipes negociaron en París tanto como lo hicieron en Madrid.

54. LÉVY, 1969, t. II: 405

55. AMAE, Correspondance Politique, Espagne, tome 195, f. 129. Carta de Desmaretz a Amelot, Versalles, 20 de febrero de 1709

56. Dahlgren, 1909; Kamen, 1974; Pérez-Mallaina Bueno, 1982; Hrodej, 2006.

57. LÉVY, 1969, t. I: 400 y 408. 
Las múltiples contradicciones en las políticas de Luis XIV y Felipe V son menores si se analizan los compromisos a los que dieron lugar. Esta perspectiva puede extenderse al comercio. Durante mucho tiempo, las represalias fueron una práctica de guerra que afectó a los mercaderes. Las prohibiciones de comerciar con los adversarios fueron, de hecho, eludidas la mayoría de las veces o incluso enmendadas directamente por el soberano. Las necesidades económicas del conflicto se imponían, ya que también correspondían a momentos de intensos intercambios entre la corona y los comerciantes, quienes no dudaban en expresar al soberano sus demandas, caso del alivio de la presión fiscal.

\section{HACER LA GUERRA O MANTENER EL COMERCIO}

La guerra no prohibía el comercio. Si se tomaban medidas extraordinarias para defraudar a los comerciantes extranjeros, en realidad, se daba paso, a formas de acomodación. Los estudios de las diversas fronteras marítimas o terrestres han puesto de relieve hasta qué punto no fueron herméticas. A veces se convirtieron en zonas de intenso comercio, caso de la frontera con Cataluña. Más que los límites geográficos de la soberanía, los márgenes aduaneros fueron los que trataban de eludir los comerciantes. En I709, el intendente del Rosellón, d'Albaret, intervino a favor de la exportación de ganado para el ejército del duque de Noailles, entonces en el principado catalán inmerso en la guerra contra Carlos III de Austria ${ }^{58}$. Solicitó una exención de impuestos, al igual que los comerciantes Jaureguiberry y Pierre Doré lo habían exigido al subdelegado de Béarn. No era la primera vez que defendía a los comerciantes, pues ya lo había hecho en I69859. Así, la protección de los mercaderes servía para garantizar un comercio considerado esencial para el abastecimiento de las tropas.

Durante la guerra de la Sucesión española muchos comerciantes aprovecharon la oportunidad del acercamiento político entre las Dos Coronas para obtener ventajas. El comercio no solo se limitó a los barcos de los malouins que se dirigían a la Mar del Sur. Numerosas cartas de mercaderes destacan cómo se adaptaron a las nuevas circunstancias políticas. Fueron alentados por ambas monarquías borbónicas, que organizaron institucionalmente la consulta a los círculos mercantiles a través de la Junta de Restablecimiento de Comercio en España y las mencionadas Cámaras de Comercio en Francia. Un estudio de los documentos oficiales de ambas instituciones revela que tales corporaciones comerciales utilizaron estos instrumentos para dar a conocer sus posiciones y deseos, como demuestran numerosas memorias ${ }^{60}$.

En el seno del Conseil de Commerce de Francia se discutieron los aranceles aduaneros, los tipos de cambio, el transporte de cereales e, incluso, las orientaciones

\footnotetext{
58. Carta de d'Albaret a Desmaretz, Perpiñán, 25 de agosto de 1709, cfr. BoISLISLE ET BROTONNE, t. III, 1878:

59. Cartas de Basville a Desmaretz, 2 y 30 de septiembre de 1698, cfr. BoISLISLE ET BrotonNE, t. I, $1878: 488$.

6o. El enfoque aquí es de la consulta en Francia. Las modalidades de los debates en España serán objeto de un artículo específico posterior.
} 205 . 
de las grandes firmas comerciales como la Compañía de Guinea, que se especializó en el tráfico de esclavos desde la concesión del asiento por Felipe $V$ en el verano de I70I. Los informes y opiniones preparados por los propios mercaderes se examinaron colectivamente. Las asambleas comerciales guiaron las respuestas del ministro de Finanzas, informándole de su posición común, ya que actuaron como foros de discusión entre los diputados y oficiales de Luis XIV, y entre los propios diputados. Como cajas de resonancia de las preocupaciones de las élites comerciales, parecen ser un espacio privilegiado de debate, como se desprende de las ya estudiadas memorias de Boisguilbert ${ }^{61}$.

Ya en I7or, se consultó al Conseil comercial con el fin de elaborar un inventario comercial y proponer formas de desarrollarlo. La mayoría de los diputados presentaron un informe que contenía críticas sobre los impuestos, el arrendamiento, los aranceles aduaneros, la manipulación de la moneda y, en general, la situación de los negocios $^{62}$. El tono de estas propuestas reflejó las ideas de sus autores, comerciantes, armadores o mercaderes. Fueron remedios muy concretos con propuestas emanadas de hombres versados en la materia. Muchas de ellas fueron confidenciales, dado que no era raro que la política real fuera cuestionada y desafiada. Estas memorias, escritas en I70I, representaron una crítica violenta a la política de Colbert. Jean Anisson, el diputado de Burdeos, escribió cómo «Nous devons rejeter les maximes de Colbert ${ }^{63}$. Las guerras y los aranceles habían desviado a los extranjeros del comercio local, mantenido con los regnícolas. Así, no resulta de extrañar que lamentasen los obstáculos que se les ponían en la ruta comercial con las islas Británicas.

La alianza política de las cortes de Madrid y Versalles despertó el interés de unos comerciantes que esperan beneficiarse de las condiciones ventajosas que reportaría tal unión. Además de los arreglos ya referidos, los círculos mercantiles se dirigieron a las respectivas autoridades para sugerir las medidas que serían más útiles. Así, en I705 se negoció entre el embajador de Luis XIV, Amelot de Gournay, y los ministros madrileños un acuerdo para la exportación de la lana española, contando con la implicación de los propios mercaderes ${ }^{64}$. El éxito de la resolución subraya la medida en que los exportadores de lana hispanos pudieron asegurar un comercio beneficioso. El potencial económico también estaba siendo valorado por los comerciantes establecidos in situ. En I707, se envió un memorial a Francia en el que los detalles de las producciones del reino de Valencia muestran que el autor era un comerciante galo perfectamente informado de la situación económica ${ }^{65}$. De hecho, la reconquista de este territorio por los ejércitos de Felipe $\mathrm{V}$, sin duda, le animó a defender sus intereses preestablecidos.

Las tensiones entre el deseo de hacer la guerra y el propósito de garantizar las actividades mercantiles fueron muy recurrentes. Al igual que con los regresos de las

\footnotetext{
61. MCCOLLIM, 2012: 149, 150 y 152.

62. SCOVILLE, 1962: 232.

63. SCOVILLE, 1962: 233 .

64. HANOTIN, 2016: 306.

65. ANOM, 2400, COL 7, Mémoire sur les mesures à prendre pour augmenter le commerce dans le royaume de Valence, 1707.
} 
flotas americanas, las decisiones adoptadas dieron lugar a numerosas discusiones en las que confluían los objetivos políticos con imperativos comerciales. En este marco, las élites negociadoras estuvieron invitadas para expresar sus pareceres. Si Luis XIV mantuvo una política ambigua hacia su nieto en lo que respecta a las salidas a la Mar del Sur, aplicó exactamente el mismo criterio con sus súbditos y ciudades portuarias. La concesión de pasaportes a los comerciantes neerlandeses que fueron a Burdeos para vender la producción de aguardientes y licores fue un claro ejemplo de ello. En esta urbe atlántica, la exportación de vino era una prioridad. Sin embargo, la venta de estos productos dependía de los holandeses, o de naturales de potencias neutrales como suecos y la Liga Hanseática. Algunas ciudades, como la propia capital de Guyenne, estuvieron a favor de aumentar en su beneficio el número de pasaportes en tiempos de guerra para los barcos de tales naciones, mientras que otras, como Dunkerque y Saint-Malo, se opusieron a ello por estar tradicional y estrechamente ligadas a tales negocios ${ }^{66}$. La cuestión de los pasaportes centró entonces las sesiones del Conseil de Commerce, aparte de influir en las relaciones entre las cortes de Versalles y Madrid durante el conflicto. De hecho, su concesión no solo molestaba a los corsarios de Saint-Malo o Dunkerque, sino también a los de Vizcaya. Las tensiones generadas entre los diferentes intereses se hacían patentes en las cartas. Mientras que la cámara de comercio podía intercambiar y mantener correspondencia directa con los ministros reales, la situación con el diputado era diferente, pues este último estaba obligado a mantener en secreto las deliberaciones del Conseil de Commerce. Fénelon, en cambio, no podía expresarse con total libertad durante el curso de tales discusiones. Así, cuando en i7o8 quiso proponer a las cámaras de comercio que los neerlandeses pudiesen llevar alimentos a las colonias, en contradicción con el monopolio exclusivo que tenía el pueblo de Burdeos, utilizó una fórmula sibilina ${ }^{67}$. Para los comerciantes de esta ciudad portuaria se trataba de asegurar el mantenimiento de sus exportaciones. El embajador francés en Madrid sería desde entonces encargado de obtener un decreto que prohibiera a los corsarios vizcaínos atacar a los barcos holandeses que portaban pasaportes franceses. Felipe $V$ firmó el primer decreto el to de diciembre de $1705^{68}$. Con posterioridad, la orden sería ratificada el 2I de noviembre de $1706^{69}$. Cuando en I707 se tomó la decisión de renovarla una vez más, fueron los comerciantes los primeros en ser advertidos, incluso, antes de que se conociera la información oficial $^{70}$. Apenas un año después, en 1708 , se planeó una otra ampliación ${ }^{71}$.

66. HUETZ DE LEMPS, 1975 .

67. «Deux affaires de la dernière conséquence pour le commerce ont été proposées, dont une regarderait plus particulièrement l'intérêt du commerce de Bordeaux, et desquelles il ne m'est pas permis de parler, (elles) paraissent être dans la meilleure main du monde, la fin de ces deux points n'étant pas pour un avantage mais un très grand dommage que nous éviterions ». Cfr. BUTEL, 1988: 39.

68. AN, Affaires Étrangères, B"I 324. Real decreto de Felipe V, Madrid, 10 de diciembre de 1705; AMAE, Correspondance Politique, Espagne, tome 154, f. 14. Carta de Chamillart a Amelot, Fontainebleau, 15 de octubre de 1705. Prohibió a los corsarios vizcaínos arrestar cualquier barco con pasaporte del Rey de Francia.

69. AN, G7 1092. Carta de Amelot a Desmaretz, Madrid, 14 de febrero de 1707.

70. AMAE, Correspondance Politique, Espagne, tome 173, f. 56. Carta de Chamillart a Amelot, Versalles, 3 de julio de 1707.

71. AN, Marine, B² 208, ff. 325-328. Carta de Pontchartrain a Amelot, Versalles, 18 de julio de 1708. 
La cuestión de los pasaportes fue esencial al articular las necesidades comerciales, las de garantizar el tráfico con fines militares, y las de hacer guerra a toda costa. Las negociaciones apuntaban a la intervención de los comerciantes. Si bien se han conservado pocos documentos intercambiados entre las élites mercantiles y los círculos de poder sobre este respecto, en muchas ocasiones los despachos de los ministros, oficiales y asesores advierten tal mediación. Así, hasta la pérdida casi definitiva de Flandes en el verano y otoño de I706, este affaire declinado en mantener o no la introducción de los bienes holandeses en los Países Bajos españoles fue objeto de discusiones entre el conde de Bergeick y d'Aguesseau, el presidente del Conseil de Commerce ${ }^{72}$. En esta materia, también se consultó a los comerciantes, ya que se hizo referencia a las «asambleas de comercio celebradas en Bruselas». Desde Flandes se mantuvieron intensos intercambios con el Hainaut francés. Los maestros herreros se alarmaron cuando una alteración en los aranceles aduaneros amenazó con perturbar el equilibrio entre el precio del hierro comprado en los Países Bajos bajo soberanía hispana y las mercancías producidas en Francia. En dos ocasiones, los pareceres proporcionados por los círculos económicos estuvieron de acuerdo con las decisiones tomadas ${ }^{73}$.

La actividad de las aduanas, al dar lugar a numerosos litigios, también reveló las múltiples intervenciones de los comerciantes ante distintas autoridades. Suelen presentarse en forma de carta en la que se quejaban de una injusticia o solicitaban una exención. Los nombres de las firmas o comerciantes se expresan al leer los votos de los ministros. Por ejemplo, los banqueros florentinos instalados en Madrid, Cambi y Spinelli, pidieron al embajador de Felipe $V$ en la corte francesa, el duque de Alba, que enviara 100.000 pesos en I709 porque querían traspasarlos a Marsella ${ }^{74}$. Para tal fin, estos poderosos y reconocidos financieros italianos lograron transmitir su petición en los círculos del soberano.

En el contexto de las nuevas relaciones entre Francia y España, el tránsito de mercancías a través de Bayona fue objeto de numerosos debates y discusiones. En diciembre de I705, el conde de Aguilar, que había ido a Versalles con la misión de informar a Luis XIV sobre la situación en España, criticó severamente el trato desigual que se daba a los comerciantes: los barcos neerlandeses obtenían pasaportes para negociar en Burdeos y Bayona cuando se les prohibía permanecer en los puertos españoles ${ }^{75}$. El conde de Aguilar se hizo eco entonces de las dificultades que atravesaban las comunidades mercantiles españolas y, más ampliamente, de los súbditos que no podían pagar los impuestos. En I709, el duque de Gramont también transmitió al contralor general de Finanzas un memorial elaborado por los comerciantes de Bayona, alarmados por la supresión de las exenciones que

72. AN, $F^{12}$ 121, ff. 35-34. Carta de D’Aguesseau a Bergeick, 1705.

73. Carta de Doujat a Desmaretz, 30 de junio de 1710, cfr. BoISLISLE et BrotONNE, 1874, t. III: 298 ; LEQUEUX, 1933: 14 .

74. AHN, Estado, legajo 364. Carta del duque de Alba a Joseph de Grimaldo, París, 29 de abril de 1709.

75. AGS, Estado, legajo 4301. Copia del memorial que en 10 de diciembre de 1705 ha presentado, en Versalles, el conde de Aguilar, sobre puntos del comercio; a Mr. de Chamillart, el marqués de Torssi, y Monsieur de Pontchartrain. La respuesta de los ministros franceses está en AMAE, Correspondance Politique, Espagne, tome 163, ff. 62-64. 
favorecían el tránsito de mercancías de Flandes a España ${ }^{76}$. En varias ocasiones, se intentó promover el comercio hispanofrancés, moderando los derechos de aduana y los impuestos. Por ejemplo, Felipe V suprimió los derechos de alcabala y cientos para las mercancías galas a su entrada en España por un decreto del 9 de noviembre de $1708^{77}$. Los vinos de Languedoc también estaban sujetos a una moderación de las tasas impositivas ${ }^{78}$. El incumplimiento de estos privilegios dio lugar inmediatamente a las quejas de los comerciantes, que consiguieron ganar su caso, ya que su demanda correspondía a un objetivo político de las Dos Coronas. Los mercaderes de Bayona aprovecharon el nuevo contexto para promover sus intereses, que estaban estrechamente vinculados al comercio con España.

Los comerciantes de las tres Provincias Vascas adoptaron la misma actitud, defendiendo amargamente sus privilegios. Las mercancías francesas importadas estaban exentas del Io\% de derechos de importación cuando se destinaban a Guipúzcoa y Vizcaya. La frontera aduanera se fijó entonces en el río Ebro. Por real cédula del 2I de diciembre de I7I7, tras una real orden del 3I de agosto de I7I7, Felipe V deseó completar un proceso de uniformización fiscal sobre las normas castellanas ${ }^{79}$. El objetivo era alinear los límites aduaneros con las demarcaciones políticas del reino, lo que, a la postre, privó a los súbditos felipistas de sus privilegios. Los comerciantes franceses se preocuparon cuando los oriundos de dichas provincias se rebelaron contra su soberano ${ }^{80}$. La oposición local, conocida como la Machinada, logró que Felipe V restituyese la línea de la aduana donde estaba previamente. Además, el monarca se tomó el tiempo de tranquilizar a los comerciantes franceses con una carta circular, ilustrando la necesidad de preservarlos ${ }^{8 \mathrm{r}}$.

Esta oposición de los comerciantes también se insertó en un escenario político de inestabilidad. Desde la muerte de Luis XIV en I715, el duque de Orleáns, regente de Luis XV, no compartía la estrategia de Felipe V en el Mediterráneo. Las disensiones entre las dos cortes condujeron a una guerra entre I7I9 y I72I ${ }^{82}$. Este enfrentamiento, que situó a Francia con gran parte de los partícipes de la antigua Gran Alianza antiborbónica de La Haya, se libró, sobre todo, en la frontera del río Bidasoa cuando las tropas francesas invadieron Guipúzcoa. Esta situación puede explicar por qué Felipe $\mathrm{V}$, una vez recuperados estos territorios, quiso pacificar rápidamente sus relaciones con sus súbditos. Además, el duque se había ocupado de salvar a la élite mercantil, consciente de que tendría que hacer las paces con su primo Borbón y, así, trataría de minimizar los rigores del conflicto contra los mercaderes. Al día siguiente de la declaración de guerra contra España, el regente se preocupó de proteger a todos los comerciantes españoles y sus propiedades presentes en el reino

76. Carta del duque de Gramont a Desmaretz, Bayona, 30 de agosto de 1709, cfr. BoISLISLE et BROTONNE, 1874, t. III: 207.

77. Carta de Desmaretz a Amelot, Versalles, 15 de octubre 1708, cfr. BoISLISLE et BrotonNe, 1874, t. III: 48-49.

78. Carta de Bâsville a Desmaretz, 8 de noviembre de 1708, cfr. BoIsLisLe et BrotonNE, 1874, t. III: 69.

79. Ṕ́rez SARRIón, 2012: 261-262.

80. Pontet-Fourmigué, 1986, t. III: 819-820.

81. AN, AE, B"I 341. Carta circular de Felipe V, octubre 1718, cfr. Pontet-Fourmigué, 1986, t. III: 821.

82. LABOURDETTE, 2001: 355-357. 
galo, prohibiendo cualquier forma de represalia o vejación contra ellos ${ }^{83}$. Felipe $\mathrm{V}$, por su parte, ya había adoptado disposiciones similares en sus jurisdicciones ${ }^{84}$. Si las leyes de la guerra eran siempre tan estrictas, resultaba difícil violar los derechos y propiedades de los comerciantes, quienes sabían cómo defenderse, hacerse oír en los círculos regios y estaban capacitados para adaptarse a circunstancias políticas inestables. Por su parte, los soberanos y sus ministros no podían ignorar los agravios de los mercaderes a los que intentaban anticiparse o, en su defecto, impedirlos, como en la guerra de la Cuádruple Alianza. Era evidente que la presión fiscal sobre los recursos económicos era beneficiosa si se mantenía la actividad comercial. Esta dependencia también se refleja en la circulación de capitales, es decir, la liquidez monetaria que posibilitaba el comercio.

\section{CIRCULACIÓN DE EFECTIVO}

Los comerciantes, a menudo, actuaron ante el rey en relación con el dinero efectivo. Ya se ha señalado cómo el arribo de los metales preciosos de América permitió financiar la guerra librada por Luis XIV y Felipe V contra Carlos III de Austria y sus aliados. La idea de que la corte de Versalles dominase a la corte de Madrid ha prevalecido por mucho tiempo, si bien no resulta del todo clara. Las decisiones se negociaron más a menudo que, por contra, se impusieron. Cuando llegaban los metales preciosos, la mayoría de las veces a las costas de Francia, las discusiones entre las cortes de Versalles y Madrid se recrudecieron. El Consejo de Indias criticó la falta de respeto a la exclusión de los extranjeros del comercio americano, mientras que el embajador francés señaló los numerosos gastos generados en el conflicto en nombre de Felipe V. Sin embargo, sería reduccionista limitar este debate a un intercambio de pareceres cortesanos, pues los comerciantes participaron muy a menudo en tales discusiones. Al igual que en los ejemplos anteriores, también intervinieron en las mudanzas del poder para alertar a los nuevos ministros acerca de las decisiones que se estaban considerando. Sin embargo, para el contralor general de Finanzas, Desmaretz, era un imperativo que el dinero circulase y, así, alcanzase a todo el comercio. Por ello, cada arribo de barcos procedentes de América era seguida muy de cerca en las esferas cortesanas y comerciales. No solo se consultaba a la comunidad mercantil, sino que también se le informaba o se le advertía si era preciso. Cuando las noticias de la captura de los galeones españoles por parte de una flota británica en el Caribe (I708) comenzaron a circular en Europa, los mercaderes tomaron la delantera asegurando sus efectos ${ }^{85}$. Como en los casos

83. Ordonnance du roy qui permet aux sujets du roy d'Espagne de demeurer en France pendant six mois, à compter du jour de ladite ordonnance, pendant lequel temps, ils pourront vendre \& transporter seurement leurs marchandises \& autres biens, París: Imprimerie royale, 1719.

84. BnF, Ms. 3189, Déclaration faite par le roy catholique en faveur des négocians françois, du $9^{e}$ novembre 1718 ; déclaration du roy d'Espagne, 25 décembre 1718.

85. «Nous n'avons pas de nouvelles certaines de la prise des galions, cependant on m'écrit d'Hollande qu'on commence à la croire et que dans l'incertitude des négociants font asseurer à 50 pour cent les effets qu'ils ont sur ces galions. » AN, Marine, B² 209, f. 274. Carta de Pontchartrain a Amelot, Versalles, 20 de octubre de 1708. 
mencionados, toda la asistencia financiera a la Corona dio lugar a una indemnización. En consecuencia, el contralor general impuso un indulto o un impuesto específico después de llegar a un compromiso con las élites comerciales. En I708, el duque de Gramont, gobernador de Bayona, advirtió a Desmaretz que una flota había llegado al puerto guipuzcoano de Pasajes. Después de algunas discusiones, este último ministro decidió fijar el indulto en solo el uno por ciento, demostrando que Michel Amelot tenía razón ${ }^{86}$. Era mejor que el dinero se acuñara en las cecas y casas de la moneda que recalar fraudulentamente a las Provincias Unidas o Gran Bretaña. En varias ocasiones, el embajador Amelot hubo de defender los derechos de los comerciantes galos ${ }^{87}$. En I7II, a algunos franceses se les concedió permiso para viajar a las Indias con la condición de que pagaran los impuestos debidos a Felipe V. A su regreso a Francia, el contralor general de Finanzas defendió el libre disfrute de sus efectos sin exención alguna, pero abogó por la confiscación en caso de fraude ${ }^{88}$. Los comerciantes también mostraron solidaridad entre sí. Cuando el armador La Lande-Magon y los capitanes Saint-Jouan y Porée fueron amenazados por el intendente con ser detenidos por negarse a pagar un indulto, el diputado de la ciudad de Saint-Malo en el Conseil de Commerce advirtió de los riesgos de hacer detener a un comerciante ${ }^{89}$.

La influencia de los comerciantes se medía por su capacidad para combatir las ideas de los banqueros y financieros más importantes de la corte de Luis XIV. Los archivos no siempre revelan las intervenciones de las comunidades mercantiles con las distintas esferas del poder, aunque sí existieron. En I708, en banquero Romet propuso la creación de un banco, lo que provocó que los diputados del Commerce se movilizasen y transmitiesen la viva oposición de los círculos mercantiles hostiles a esta iniciativa. Con tales miembros, el rechazo fue unánime ${ }^{90}$. En I709, la cuestión de la creación de otro banco reaparecióor ${ }^{91}$. Nicolas Desmaretz consideró entonces la creación de una institución cuyos fondos se compusiesen de la deuda del soberano circulando en forma de papel moneda. Esta innovación alarmó a los núcleos económicos y el rumor se extendió tan rápido que el ministro se vio obligado a dar marcha atrás en su decisión, a pesar de que esta había sido iniciada por una propuesta de Samuel Bernard, uno de los más importantes financieros del mercado parisino. Varios círculos comerciales intervinieron ante el ministro. En I7Io, el propio Desmaretz señaló que la creciente escasez de efectivo en el comercio comenzaba a producir los efectos negativos que le habían advertido los mercaderes ${ }^{92}$. Finalmente, rechazó la idea de crear un banco, pues el objetivo que se buscaba era promover la circulación de dinero en efectivo, cuya escasez era catastrófica para los

86. Carta de Gramont a Desmaretz, Bayona, 27 de agosto de 1708, cfr. BoISLISLE et Brotonne, 1874, t. III: 77.

87. SHD, $A^{1}$ 2048, ff. 187-190. Carta de Amelot a Chamillart, Madrid, 21 de marzo de 1707.

88. Carta de Desmaretz a Pontchartrain, Versalles, 23 y 24 de abril de 171l, cfr. BoIsLISLE et BrotonNE, 1874, t. III: 369 .

89. Carta de Ferrand, intendente de Bretaña, a Desmaretz, 29 de septiembre de 1710, cfr. BoISLISLE et BROTONNE, 1874, t. III: 318.

90. Carta de Le Bartz a Desmaretz, 7 de diciembre de 1708, cfr. BoIsLISLE et BrotonNE, 1874, t. III: 642.

91. Guerre, 2019: 337-340.

92. Guerre, 2019: 342-344. 
intereses generales. Una vez más se observa cómo raramente se tomaron decisiones financieras sin tener en cuenta la opinión de los comerciantes.

\section{CONCLUSIONES}

Las interacciones entre las elites mercantiles y los poderes fácticos aún no han sido estudiadas en profundidad. A menudo aparecen solo de manera indirecta o transversal en los archivos históricos. Sin embargo, durante la guerra de Sucesión española, se recurrió al constante parecer del comercio, ya fuera en Francia o en la España borbónica, para que sus miembros hiciesen una contribución esencial al esfuerzo bélico. La presión fiscal ejercida sobre las actividades comerciales dio lugar a numerosas negociaciones y a la elaboración de compromisos de los que los comerciantes no siempre parecían verse favorecidos. De hecho, el análisis de estas relaciones revela cómo los vínculos entre los mercaderes y los círculos de poder se rigieron por una forma de acuerdo negociado. Esta era la condición necesaria para que el soberano obtuviera ingresos fiscales cuando lo requiriese de cara a mantener las actividades comerciales en tiempos de guerra.

En el convulso primer cuarto del siglo XVIII, la adaptación de las élites mercantiles hispanofrancesas a las condiciones políticas fue evidente, logrando aprovechar la alianza dinástica de la Casa de Borbón en pro de sus negocios. Cuando las dificultades se acumularon después de los acuerdos de Utrecht, Rastatt y Baden (I713I7I5) y de la muerte de Luis XIV, así como por causa de las políticas de Felipe V y su segunda esposa Isabel de Farnesio, los hombres de negocios habrían alcanzado tal poder que cominaría al rey de España y al regente francés, duque de Orleans, a contemporizar y favorecerles. A la época de las represalias, tan comunes en el Seiscientos, le siguió la era de una supuesta colaboración. Si la guerra provocaba, como siempre, una crisis de gran impacto para el comercio, las elites mercantiles encontrarían los medios para hacer valer sus intereses o sacar beneficio de la situación. 


\section{BIBLIOGRAFÍA}

Albareda Salvadó, Joaquím, La Guerra de Sucesión de España (I70o-I7I4), Barcelona, Crítica, $20 I 0$.

Alloza Aparicıo, Ángel, Diplomacia caníbal: España y Gran Bretaña en la pugna por el dominio del mundo, I638-I660, Madrid, Biblioteca Nueva, 2015.

Alloza Aparicio, Ángel, « El comercio francés en España y Portugal. La represalia de i635 », en Carlos Martínez Shaw y José María Oliva Melgar (eds.), El sistema atlántico español (siglos XVII-XIX), Madrid, Marcial Pons, 2005: I27-I62.

Alloza Aparicıo, Ángel,, « «La represalia de Cromwell» y los mercaderes ingleses en España (I655-I667)», Espacio, tiempo y forma. Serie IV, Historia moderna, I3 (2000): 83-II2.

BARBICHE, Bernard, Les Institutions de la monarchie française à l'époque moderne, París, PUF, $200 I$.

BArrios, Feliciano, Los Reales Consejos. El gobierno central de la Monarquía en los escritores sobre Madrid del siglo XVII, Madrid, Universidad Complutense - Facultad de Derecho, I988.

DE Boislisle, Arthur-Michel y de BRotonne, Pierre, Correspondance des contrôleurs généraux des finances avec les intendants des Provinces, París, I874-1897, 3 tomos.

Butel, Paul (ed), Histoire de la Chambre de commerce et d'industrie de Bordeaux: des origines à nos jours, I705-I785, Burdeos, Chambre de commerce et d'industrie de Bordeaux, I988.

CArdim, Pedro, Herzog, Tamar y Ruiz Ibáñez, José Javier, Polycentric monarchies: how did early modern Spain and Portugal achieve and maintain a global hegemony?, Brigthon, Sussex Academix Press, 2012.

Cornette, Joël (ed.), La Monarchie entre Renaissance et Révolution, I515-I792, París, Seuil, 2000.

DAHLGREN, Erik Wilhelm, Les relations commerciales et maritimes entre la France et les côtes de l'océan Pacifique, tomo I, París, H. Champion, I909.

Díaz Blanco, José Manuel, Así trocaste tu gloria: guerra y comercio colonial en la España del siglo xvil, Madrid, Marcial Pons Historia-Instituto Universitario de Historia de Simancas, 2012.

FÉLIX, Joël, Économie et finances sous l'Ancien Régime: Guide du chercheur, I523-I789, Vincennes, Institut de la gestion publique et du développement économique, I994.

Guerre, Stéphane, Nicolas Desmaretz: le Colbert oublié du Roi-Soleil, Ceyzérieu, Champ Vallon, 20I9.

Habermas, Jürgen, The Structural transformation of the public sphere, Cambridge, MIT Press, I962.

Hanotin, Guillaume, Ambassadeur de deux couronnes: Amelot et les Bourbons entre commerce et diplomatie, Madrid, Casa de Velázquez, 2018.

Hanotin, Guillaume,, «L'exportation des laines espagnoles en temps de guerre: du commerce à la diplomatie durant la guerre de succession d'Espagne », en MarieBernadette Dufourcet-Hakim y Josette Pontet (eds.), Guerre et paix: les enjeux de la frontière franco-espagnole (XVI ${ }^{e}$-début XIX ${ }^{e}$ siècle), Burdeos, Presses Universitaires de Bordeaux, 2016: 299-316.

Hermant, Héloïse, Guerres de plumes: publicité et cultures politiques dans l'Espagne du XVII siècle, Madrid, Casa de Velázquez, 2012. 
Hrodej, Philippe, «Marine et diplomatie: les vaisseaux français, un outil au service du Bourbon de Madrid et de l'empire espagnol d'Amérique (I700-I713) », en Christian Buchet (dir.), La mer, la France et l'Amérique latine, Paris, PUPS, 2006: 27-43.

HuETZ DE LemPS, Christian, Géographie du commerce de Bordeaux à la fin du règne de Louis XIV, París-La Haya, Mouton, 1975.

Gauci, Perry, The Politics of Trade: The Overseas Merchant in State and Society, I660-I720, Oxford, Oxford University Press, 2001.

JAMBU, Jérôme, « Frauder avec la monnaie à l'époque moderne, de Louis XIV à la Révolution », en Gérard Béaur (ed.), Fraude, contrefaçon, contrebande de l'Antiquité à nos jours, Ginebra, Librairie Droz, 2007: 249-278.

Kamen, Henry, La guerra de Sucesión en España, I700-I715, Barcelona, Crítica, I974.

Labourdette, Jean-François, Philippe V, réformateur de l'Espagne, París, Sicre Éditions, $200 \mathrm{~s}$.

LE MAO, Caroline, Les villes portuaires maritimes dans la France moderne, $\mathrm{XVI}^{e}$-XVIII ${ }^{e}$ siècle, París, Armand Colin, 2015.

LeQueux, André, «L'industrie du fer dans le Hainaut français au XVIII ${ }^{e}$ siècle », Revue du Nord, I9-73 (1933): 528.

LeSPAGNOL, André, Messieurs de Saint-Malo: une élite négociante au temps de Louis XIV, SaintMalo, Éditions de l'Ancre de marine, I99I.

LÉvY, Claude-Frédéric, Capitalistes et pouvoir au Siècle des Lumières, París-La Haya, Mouton, I969, 3 volúmenes.

López Campillon, Rosa María, «Daniel Defoe, propagandista político al servicio de los intereses comerciales británicos durante la guerra de Sucesión española (I702-I7I4)», en Pedro Losa Serrano, Rosa María López Campillo, Ramón Cózar Gutiérrez, Christopher Storrs, Porfirio Sanz Camañes y Ramón Sánchez González, La guerra de Sucesión española y la opinión publica hispano-británica, Madrid, Sílex, 2014: 3I-54.

LORENZo LozANo, Julia, Franceses en Valencia durante el reinado de Carlos II entre la atracción y el rechazo, tesis doctoral bajo la dirección de Emilia Salvador Esteban, Valencia, Universitat de València, 2015.

Mateos Royo, José Antonio, «Pensamiento mercantilista y circulación monetaria en el Reino de Aragón durante el siglo XVII », Brocar: cuadernos de investigación histórica, 28 (2004): I67-I94.

McCollim, Gary B., Louis XIV's Assault on Privilege: Nicolas Desmaretz and the Tax on Wealth, Rochester, University of Rochester Press, 2012.

MÉZIN, Anne, « Le consulat de France à Cadix: des hommes et une fonction (I666-I740) », en Anne Mézin y Anne Pérotin-Dumon (eds.), Le consulat de France à Cadix: Institution, intérêts et enjeux (I666-I740), Pierrefitte-sur-Seine: Publications des Archives nationales, 2016.

Molas Ribalta, Pere, « La junta general de comercio y moneda: la institución y los hombres », Cuadernos de Historia. Anexos de la Revista Hispania, 38/9 (1978): I-38.

Pérez-Mallaína Bueno, Pablo Emilio, Política naval española en el Atlántico, I70o-I7I5, Sevilla, Escuela de Estudios Hispano-Americanos, I982.

Pérez Sarrión, Guillermo, La Península comercial: mercado, redes sociales y Estado en España en el siglo XVIII, Madrid, Marcial Pons Historia, 2012.

Pontet-Fourmigué, Josette, Bayonne, un destin de ville moyenne à lépoque moderne: étude de l'agglomération bayonnaise de la fin du XvII siècle au milieu du XIXe siècle, thèse de doctorat sous la direction de Jean-Pierre Poussou, Université Paris-Sorbonne (Paris IV), I986, 3 vols.

QUÉNET, Maurice, «Un exemple de consultation dans l'administration monarchique au XVIII ${ }^{e}$ siècle », Annales de Bretagne et des pays de l'Ouest, 85/3 (I978): 449-485. 
ROBERTS, Penny, «La monarchie consultative, mythe ou réalité: Les états généraux et le " père du peuple », 1560-I6I4 ", en Michel De Waele (ed.), Lendemains de guerre civile: réconciliations et restaurations en France sous Henri IV. Les collections de la République des lettres. Symposiums, Québec, Presses de l'Université de Laval, 20II: 89-ı08.

Scoville, Warren C., «The French Economy in I700-I70r: An Appraisal by the Deputies of Trade », The Journal of Economic History, 22/2 (I962): 23I-252.

TARRADE, Jean, «Liberté du commerce, individualisme et État. Les conceptions des négociants français au xvilI ${ }^{\mathrm{e}}$ siècle », Cahiers d'économie politique, (1996): I75-I9I.

ULBERT, Jörg, «Introduction. La fonction consulaire à l'époque moderne: définition, état des connaissances et perspectives de recherche ", en Jörg Ulbert y Gérar Le Bouëdec (eds.), La fonction consulaire à l'époque moderne: L'affirmation d'une institution économique et politique (I500-I800), Rennes, Presses universitaires de Rennes, 2006 : 9-20.

VAN DEN TOL, Joris, « Monopolizing arguments: outside lobbying in the Dutch Republic for free trade to Brazil, I630-I638 », en Amélia Polónia y Cátia Antunes (eds.), Mechanisms of Global Empire building, Porto, CITCEM, 20I7:III-I25.

VILA VILAR, Enriqueta, El consulado de Sevilla de mercaderes a Indias: un órgano de poder, Sevilla, Ayuntamiento de Sevilla-Instituto de la Cultura y las Artes de Sevilla, 2016.

VAlle Pavón, Guillermina del, «Servicios financieros del Consulado de México para la guerra de Sucesión dinástica »,Mélanges de la Casa de Velázquez, 46-I (2016): 77-88. 



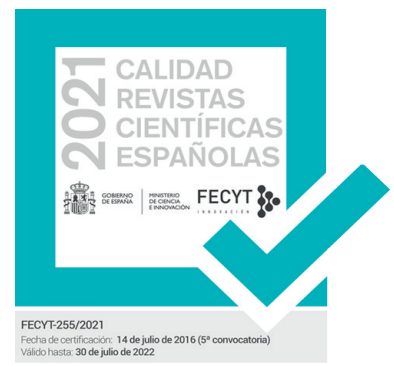

SERIE IV HISTORIA MODERNA

REVISTA DE LA FACULTAD DE GEOGRAFÍA E HISTORIA

AÑO 2021

ISSN: 1131-768X

E-ISSN 2340-1400

\section{4 \\ 西 ESPACIO, TIEMPO Y FORMA}

Monográfico - Special Issue: La política ultramarina de las monarquías ibéricas (circa 1700-1750): una historia de fracasos y éxitos relativos The Overseas Policy of the Iberian Monarchies (Circa 1700-1750): A History of Failures and Relative Successes

15 Roberto Quirós Rosado y MARIA FERnANDA BICALHO La política ultramarina de las monarquías ibéricas (circa 1700-1750): una historia de fracasos y éxitos relativos / The Overseas Policy of the Iberian Monarchies (Circa 1700-1750): A History of Failures and Relative Successes

\section{Guillaume Hanotin}

Defender negocios en tiempo de convulsión política: las elites mercantiles francesas durante la guerra de Sucesión española / Protecting Business in Time of Crisis: French Trademen during the War of Spanish Succession

\subsection{Maria Fernanda Bicalmo}

Ultramarino y el auge de los secretarios de Estado en Portugal durante la primera mitad del siglo XVIII / Sobre este modo de resolver e despachar os negócios. The decline of the Overseas Council and the Rise of the Secretaries of State in Portugal during the First Half of the $18^{\text {th }}$ Century

\section{9}

\section{VALENTINA FAVARò}

El fracaso de los proyectos de reforma en el virreinato peruano de principios

del siglo XVIII. Las propuestas de Carmine Nicola Caracciolo, príncipe de Santobuono the Eighteenth Century. The Proposals of Carmine Nicola Caracciolo, Prince of Santobuono

\section{7}

\section{ROBERTO QUIRÓS ROSADO}

Ecos de un mercantilismo truncado. El conde de Pinos Puente y la diplomacia comercial de Carlos VI en la corte de Lisboa (1723-1724) / Echoes of a Failed Mercantilism. The Count of Pinos Puente and the Commercial Diplomacy of Charles VI at the Court Of Lisbon (1723-1724)

\section{Junia Ferreira Furtado}

Portuguese America under Foreign Threat and the Creation of the Concept of uti possidetis in the First Half of the $18^{\text {th }}$ Century / La américa portuguesa bajo la amenaza exterior y la creación del concepto de uti possidetis en la primera mitad del siglo XVIII

\section{Miscelánea $\cdot$ Miscellany}

\section{José Antonio Mateos Royo}

con Cataluña / Trade Policy and Monetary Circulation in Aragon: Conflicts and Agreements with Catalonia (1535-1565)

\section{Fernando Altoé}

panegíricos atribuidos a la impresion. Un estudio de la trayectoria de dos the Trajectory of Two Panegyrics Attributed to João de Barros

\section{Francisco Velasco Hernández}

reino de Murcia (siglos XVI y XVII) / The Influence of the Berber Corsican on the Late Repopulation on the Coastal Area on the Kingdom of Murcia (XVI and XVII Centuries)

\section{José Antonio Martínez Martínez}

Criados, jornaleros y esclavos al servicio de la familia: la servidumbre de Serfdom of the Muñoz de Otálora in the $17^{\text {th }}$ Century

\section{Víctor Daniel Regalado González-Serna}

Benito de Medina a raíz de su ingreso en el cabildo catedral de Sevilla en 1669 / «Not a Single Good Portuguese». Accusations against Priest Alonso Benito de Medina when Entering the Cathedral Chapter of Seville in 1669

\section{José Herrera Reviriego}

organigrama comercial y militar de la Gober a tólo mitad del siglo XVII / "Only Time will Tell us»: The Role of Taiwan within the Commercial and Military Organization of the Philippine's Governoration during the First Half of the Seventeenth Century

\section{Manuel-Reyes García Hurtado}

de Rande, 1719-1733 / Vicissitudes of the Rescue Companies of the Sunken Ships in the Battle of Rande, 1719-1733

\subsection{Marcos de Miguel Muñoz}

Caballeros in 1769 


\section{4 ESPACIO, TIEMPO Y FORMA}

\section{Javier Tinoco Domínguez}

Tensiones sociopolíticas en el marco del catastro de Ensenada en Jerez de la Frontera: estudio de un conflicto institucional / Socio-Political Tensions within the Framework of Cadastre of Ensenada In Jerez de la Frontera: A Studying of an Institucional Conflict

\section{Pablo Fernández Albaladejo}

Fábulas de origen y gramática de nación en la España del siglo XVIII. A propósito de algunos trabajos de Francisco Martínez Marina / Origin's Fables and Grammar of Nation in the XVIII Century Spain. About some Works by Francisco Martínez Marina

\subsection{José María IÑURRITEgui Rodríguez}

Constitución increada: Francisco Martínez Marina y la crítica bíblica / Uncreated Constitution. Francisco Martínez Marina and Biblical Criticism

\subsection{David A. Abián Cubillo}

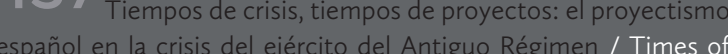
crisis, Times of Projects: The Spanish proyectismo during the Army's Crisis in the Ancient Regime

Taller de historiografía · Historiography Workshop

\section{Ensayos · Essays}

\subsection{ChrISTOPH ROSENMÜLLER}

«Tan peligrosas y feas conspiraciones»: la relación escrita por el embajador austriaco Christoph Migazzi en 1754 sobre la caída del marqués de la Ensenada / «Dangerous and Ugly Conspiracies». The Report of the Austrian Ambassador Christoph Migazzi on the Fall of the Marquis of la Ensenada in 1754

\subsection{Serge Gruzinskı}

Quelle histoire enseigner en 2021 ? / ¿Qué historia enseñar en 2021?

\subsection{Carlos Amate Pizarro}

Las relaciones hispano-chinas en el siglo XVI: síntesis e interpretación a la luz de la reciente historiografía / The Hispanic-chinese Relationship in the XVI Century: Synthesis and Interpretation in the Light of Recent Historiography

\section{Reseñas • Book Review}

521 Bolufer Peruga, Mónica, Arte y artificio de la vida en común. Los modelos de comportamiento y sus tensiones en el Siglo de las Luces, (Julio ArRoyo Vozmediano) 


\section{4 ESPACIO, TIEMPO Y FORMA}

525 Melón, Amando, Alejandro de Humboldt. Vida y obra (Carlos Martínez Shaw)

52 Commentary to Tatiana Seijas' review of The Atlantic World and the Manila Galleons: Circulation, Market, and Consumption of Asian Goods in the Spanish Empire (JosÉ LuIs GASCH TOMAS)

533 Braguier, Laurey, Servantes de dieu. Les beatas de la Couronne de Castille (1450-1600) (Manuela Águeda GARCÍA-GARRIDO)

539 Romeo, María CRuz; SAlomón, María Pilar; TABANERA, Nuria (eds.): Católicos, Reaccionarios y Nacionalistas. Política e identidad nacional en Europa y América Latina Contemporáneas (JAVIER M. Dos SANTOS)

54 Heredia López, Alfonso Jesús, El control de la corrupción en la Monarquía Hispánica. La Casa de la Contratación (1642-1660) (José Manuel Díaz Blanco)

17 Andújar Castillo, Francisco, El Atila de Madrid. La forja de un banquero en la crisis de la monarquía (1685-1715) (Aitor Díaz PAREdes)

551 Serrano Aviles, Javier y Mojarro, Jorge (eds.) Prada GonzALEZ, María (coord. de ilustraciones), En el archipiélago de la Especiería. España y Molucas en los siglos XVI y XVII (İ̃̃ıGo VALPUESTA VILLA)

555 Díaz Ceballos, Jorge, Poder compartido. Repúblicas urbanas, Monarquía y conversación en Castilla del Oro, 1508-1573 (JUAN SEbAstián Gómez GonZÁleZ)

51 Edelmayer, Friedrich, Massimiliano II, Filippo II I'Italia imperiale. II marchesato di Finale, i diritti imperiali e il «camino spagnolo» (RAFAEL VALLADARES)

56 Escribano-PÁEZ, José M., Juan Rena and the Frontiers of Spanish Empire, 1500-1540 (DAvid Martín Marcos)

56 ARnOLD, David, La Era de los Descubrimientos (1400-1600), Madrid, Alianza Editorial, 2021, 184 Pp., ISBN: 978-841362-172-2 (CARlos Amate Pizarro) 